\title{
The Human G147D-Protein Phosphatase 1 Inhibitor-1 Polymorphism Is Not Associated with Altered Clinical Characteristics in Heart Failure
}

\author{
Guoli Chen ${ }^{\mathrm{a}}$ Xiaoyang Zhou ${ }^{\mathrm{a}, \mathrm{c}}$ Anand Pathak ${ }^{\mathrm{a}}$ Gerald W. Dorn, 2nd ${ }^{\mathrm{a}, \mathrm{b}}$ \\ Evangelia G. Kranias ${ }^{a, d}$ \\ a Department of Pharmacology and Cell Biophysics, University of Cincinnati College of Medicine, Cincinnati, Ohio, \\ and ${ }^{\mathrm{b}}$ Department of Medicine, Center for Pharmacogenomics, Washington University School of Medicine, \\ St. Louis, Mo., USA; ' Department of Cardiology, Renmin Hospital of Wuhan University, Wuhan, China; \\ ${ }^{\mathrm{d}}$ Foundation for Biomedical Research of the Academy of Athens, Athens, Greece
}

\section{Key Words}

Heart failure $\cdot$ Polymorphism $\cdot$ Protein phosphatase

inhibitor-1

\begin{abstract}
Objectives: A human protein phosphatase inhibitor-1 polymorphism, G147D (c.440G >A, p.147G >D), has been previously demonstrated to blunt the contractile responses of cardiomyocytes to $\beta$-adrenergic agonists. The present study sought to examine whether the G147D inhibitor-1 polymorphism may be associated with specific clinical characteristics of heart failure carriers. Methods: Clinical information of 963 heart failure patients was analyzed according to race, inhibitor-1 genotype, treatment with $\beta$-blockers and mortality patterns. Results: The G147D inhibitor-1 genetic variant was found almost exclusively in black subjects and its frequency was similar between normals and heart failure patients, indicating that it was not a primary risk factor for developing heart failure. Comparison of the major cardiac functional parameters and transplant-free survival patterns between carrier and noncarrier patients did not reveal any significant differences. Furthermore, echocardiographic evaluation showed similar outcomes of $\beta$-blocker treatment between G147D carriers and noncarriers. Conclusions: The present
\end{abstract}

findings indicate that the human inhibitor-1 G147D polymorphism, found almost exclusively in blacks, may act as a modifier rather than risk factor in heart failure development.

Copyright $\odot 2008$ S. Karger AG, Basel

\section{Introduction}

Heart failure is a pleiotropic disease reflecting complicated interactions between individual genetic backgrounds and environmental factors. Nevertheless, depressed $\beta$-adrenergic signaling, resulting from defects in its receptor and/or downstream components, is one of the most prominent and common molecular mechanisms underlying the pathogenesis of heart failure $[1,2]$.

The functional effects of $\beta$-adrenergic agonists on cardiomyocyte contractility depend on PKA-mediated phosphorylation of multiple key intracellular proteins, including ryanodine receptor, phospholamban, L-type calcium channel and troponin I [3]. The reversal of these stimulatory effects is mediated by dephosphorylation of these

G. Chen and X. Zhou contributed equally to this work.

\section{KARGER}

๑) 2008 S. Karger AG, Basel

Fax +41613061234 E-Mail karger@karger.ch www.karger.com www.karger.com/crd
Evangelia G. Kranias, PhD

Department of Pharmacology and Cell Biophysics, University of Cincinnati

College of Medicine, 231 Albert Sabin Way

Cincinnati, Ohio 45267-0575 (USA)

Tel. +1 513558 2327, Fax +1 513558 2269, E-Mail Litsa.Kranias@uc.edu 
regulatory proteins through protein phosphatases 1 and 2. The fine balance of protein kinase and phosphatase activities is essential for proper calcium cycling and functional homeostasis in the heart. However, depressed adrenergic signaling cascade and elevated phosphatase activity tilt this balance in favor of dephosphorylation in experimental and human heart failure [4-7]. Particularly, abnormal elevation of protein phosphatase 1 (PP1) activity has been associated with depressed calcium homeostasis in failing hearts $[4,8]$.

One potential mechanism underlying the pathologically elevated PP1 activity in heart failure is the diminished restriction from its endogenous inhibitor, inhibitor-1. Inhibitor-1 potently inhibits PP1 activity upon its phosphorylation by $\beta$-adrenergic stimulation, resulting in increased cardiac contractility [5,9-11]. Consequently, cardiac overexpression of a constitutively active form of inhibitor-1 (AA 1-65, T35D) resulted in higher resistance to stress-induced cardiac remodeling and heart failure [8]. In contrast, decreased activity and/or reduced protein levels of inhibitor-1 have been identified in animal models with cardiac dysfunction and human heart failure patients $[4,7,11-14]$, suggesting that defects in inhibitor-1 activity may contribute to depressed cardiac function.

To determine whether there exist genetic variants of human inhibitor-1 that may act as direct or conjunct factors in heart failure, we sequenced the inhibitor-1 gene in heart failure patients. A human inhibitor-1 polymorphism, G147D (c.440G>A, p.147G>D), was identified almost exclusively in black subjects. Notably, expression of this polymorphism in isolated adult rat cardiomyocytes interfered with the contractile response to $\beta$-adrenergic agonists [15]. Therefore, we further analyzed the clinical information of the heart failure patients to assess whether carrying this inhibitor-1 genetic variant contributed to heart failure. The nearly equal distribution of this polymorphism in normal subjects and heart failure patients indicated that it did not independently alter the risk of developing heart failure. Furthermore, the inhibitor-1 polymorphism did not appear to modify cardiac function, the responses to $\beta$-blocker treatment or the overall mortality pattern.

\section{Materials and Methods}

\section{Study Subjects}

As described previously $[15,16]$, the human study protocols were approved by the Institutional Review Board of the University of Cincinnati. Subjects provided written informed consent. Heart failure subjects were aged $18-80$ years and had New York
Heart Association heart failure class II-IV. The study included 999 heart failure patients followed at the University Hospital, Cincinnati, between 1999 and 2004 and 357 nonaffected controls recruited from the greater Cincinnati area between 2003 and 2005. Racial classification as whites, blacks or others was self-reported. The heart failure study endpoint was death or cardiac transplantation.

\section{Genotyping}

Exons 1-6 of inhibitor-1 1 [PPP1R1A according to National Center for Biotechnology Information, PPP1R1A = protein phosphatase 1 regulatory (inhibitor) subunit $1 \mathrm{~A}$ (Homo sapiens), gene ID 5502, in chromosome 12] were screened, as described previously [15].

\section{Statistics}

For the clinical characteristics of the patients with heart failure, continuous variables are presented as mean $\pm \mathrm{SD}$, and comparisons between ethnic groups, between genotype classes within ethnic groups and between $\beta$-blocker usage groups are conducted by unpaired Student's t tests. Categorical variables are presented as proportions, and comparisons between ethnic groups and between genotype classes within ethnic groups are conducted by $\chi^{2}$ tests. Hardy-Weinberg equilibrium is assessed in each ethnic group separately by $\chi^{2}$ test. Subjects, either heterozygous (G/D) or homozygous (D/D) for the G147D polymorphism of inhibitor-1 gene, are taken together into one group, because the mutant homozygotes were too few for separate analysis. $\chi^{2}$ or Fisher's exact tests are used to test for associations between heart failure and genotype or allele within each ethnic group. Differences in time from heart failure diagnosis to endpoint were assessed using $\mathrm{Ka}$ plan-Meier curves and log-rank tests. Relative risks were obtained using Cox proportional hazards modeling. In all analyses, $\mathrm{p}<$ 0.05 was considered statistically significant.

\section{Results}

\section{Identification of Genetic Variants in the Human}

Inhibitor-1 Gene and Clinical History of Heart Failure Patients

The PP1 inhibitor-1 gene was sequenced in 181 unrelated heart failure patients recruited from the University Hospital and Cincinnati Heart Failure/Transplant Program. We identified several genetic variants in the inhibitor-1 gene (p109G $>$ E, p110 $>$ > and $\mathrm{p} 147 \mathrm{G}>\mathrm{D})$ ). Interestingly, the G147D genetic variant was identified only in black heart failure patients. Moreover, a previous study in isolated adult rat cardiomyocytes has demonstrated that overexpression of this polymorphism interfered with the contractile response of cardiomyocytes to $\beta$-adrenergic agonists [15]. Therefore, we further assessed the functional parameters in 963 heart failure patients with detailed information. These include 288 blacks, 671 whites and 4 others recruited from the University Hospital and 
Table 1. Clinical characteristics of heart failure patients by race

\begin{tabular}{|c|c|c|c|c|c|}
\hline \multirow[t]{2}{*}{ Variable } & \multicolumn{2}{|c|}{ Whites } & \multicolumn{2}{|c|}{ Blacks } & \multirow[t]{2}{*}{$\mathrm{p}$ value } \\
\hline & $\mathrm{n}$ & mean $\pm \mathrm{SD}$ & $\mathrm{n}$ & mean $\pm \mathrm{SD}$ & \\
\hline Age at onset of heart failure, years & 671 & $55.73 \pm 12.78$ & 288 & $52.66 \pm 13.33$ & 0.001 \\
\hline Weight, kg & 656 & $85.85 \pm 21.46$ & 281 & $90.68 \pm 25.99$ & 0.006 \\
\hline Height, $\mathrm{cm}$ & 649 & $172.56 \pm 14.68$ & 272 & $171.58 \pm 10.42$ & 0.314 \\
\hline Systolic BP, mm Hg & 540 & $117.73 \pm 21.25$ & 231 & $119.88 \pm 23.65$ & 0.234 \\
\hline Diastolic BP, mm Hg & 540 & $72.96 \pm 13.49$ & 230 & $75.00 \pm 14.55$ & 0.061 \\
\hline LVEDD, $\mathrm{cm}$ & 526 & $6.43 \pm 1.18$ & 254 & $6.12 \pm 1.02$ & $<0.001$ \\
\hline LVESD, $\mathrm{cm}$ & 502 & $5.08 \pm 1.38$ & 251 & $4.80 \pm 1.29$ & 0.007 \\
\hline Septal wall, cm & 476 & $1.07 \pm 0.28$ & 246 & $1.13 \pm 0.28$ & 0.018 \\
\hline Posterior wall, $\mathrm{cm}$ & 476 & $1.01 \pm 0.24$ & 246 & $1.04 \pm 0.27$ & 0.239 \\
\hline LVEF, \% & 502 & $45.83 \pm 16.25$ & 251 & $44.25 \pm 13.88$ & 0.220 \\
\hline Fractional shortening, \% & 502 & $21.74 \pm 11.19$ & 251 & $22.54 \pm 11.81$ & 0.368 \\
\hline $\mathrm{MVO}_{2}$ & 409 & $17.39 \pm 5.83$ & 137 & $15.74 \pm 5.08$ & 0.003 \\
\hline \multirow[t]{2}{*}{ Variable } & \multicolumn{2}{|c|}{ Whites } & \multicolumn{2}{|c|}{ Blacks } & \multirow[t]{2}{*}{$\mathrm{p}$ value } \\
\hline & $\mathrm{n}$ & $\%$ & $\mathrm{n}$ & $\%$ & \\
\hline Male & 464 & 69.2 & 157 & 54.5 & $<0.001$ \\
\hline \multicolumn{6}{|l|}{ Primary diagnosis } \\
\hline Idiopathic cardiomyopathy & 332 & 52.2 & 175 & 63.4 & \\
\hline Coronary artery disease & 222 & 34.9 & 44 & 15.9 & \\
\hline Other & 82 & 12.9 & 57 & 20.7 & $<0.001$ \\
\hline Cardiac-related death or received transplant & 279 & 42.1 & 80 & 28.6 & $<0.001$ \\
\hline \multicolumn{6}{|l|}{ Other risk factors or coexisting conditions } \\
\hline Hypertension & 313 & 47.2 & 227 & 79.4 & $<0.001$ \\
\hline Diabetes mellitus & 199 & 33.5 & 93 & 34.8 & 0.703 \\
\hline Hypercholesterolemia & 166 & 31.4 & 56 & 25.3 & 0.099 \\
\hline \multicolumn{6}{|l|}{ Tobacco use } \\
\hline Present user & 294 & 63.4 & 144 & 68.9 & \\
\hline Past only & 96 & 20.7 & 36 & 17.2 & \\
\hline Never & 74 & 15.9 & 29 & 13.9 & 0.374 \\
\hline \multicolumn{6}{|l|}{ Medications at entry } \\
\hline$\beta$-Blocker & 453 & 70.6 & 228 & 81.7 & $<0.001$ \\
\hline ACE inhibitor & 487 & 88.9 & 223 & 93.7 & 0.035 \\
\hline $\mathrm{ARB}$ & 80 & 38.8 & 40 & 34.8 & 0.472 \\
\hline Aldosterone blocker & 83 & 32.8 & 39 & 31.5 & 0.792 \\
\hline
\end{tabular}

Cincinnati Heart Failure/Transplant Program. The clinical characteristics of the patients are shown in table 1 according to race. Significant differences in age of clinical presentation, body weight, LVEDD, LVESD, thickness of septal wall, $\mathrm{MVO}_{2}$, gender distribution, primary diagnosis and coexistence of hypertension were identified between white and black patients. Comorbid conditions in the cohorts included hypertension (47 and 79\% in whites and blacks), diabetes (34 and 35\% in whites and blacks) and hypercholesterolemia (31 and 25\% in whites and blacks). The medications used by the patients were: $\beta$ blocker (71 and 82\% in whites and blacks), ACE inhibitor (89 and 94\% in whites and blacks), angiotensin receptorblocking agent (39 and $32 \%$ in whites and blacks) and aldosterone blocker (33 and 32\% in whites and blacks). 
Table 2. Racial distribution of inhibitor-1 G147D polymorphism

\begin{tabular}{|c|c|c|c|c|}
\hline & Patients with $\mathrm{HF}^{1}$ & Normal controls ${ }^{1}$ & OR (95\% CI) & $\mathrm{p}$ value \\
\hline \multicolumn{5}{|l|}{ Blacks } \\
\hline GG & $259(89.9)$ & $35(87.5)$ & 1 & \\
\hline $\mathrm{GD}+\mathrm{DD}$ & $28+1(10.1)$ & $5+0(12.5)$ & $0.784(0.285-2.158)$ & 0.636 \\
\hline Total & $288(100)$ & $40(100)$ & & \\
\hline Frequency of allele D, \% & 5.21 & 6.25 & $0.824(0.310-2.189)$ & 0.603 \\
\hline \multicolumn{5}{|l|}{ Whites } \\
\hline GG & $671(100)$ & $311(99.7)$ & 1 & \\
\hline $\mathrm{GD}+\mathrm{DD}$ & 0 & $1+0(0.3)$ & $0.155(0.006-3.806)$ & 0.142 \\
\hline Total & $671(100)$ & $312(100)$ & & \\
\hline Frequency of allele D, \% & 0 & 0.16 & $0.155(0.006-3.806)$ & 0.404 \\
\hline \multicolumn{5}{|l|}{ Others } \\
\hline GG & 4 & 9 & & \\
\hline $\mathrm{GD}+\mathrm{DD}$ & 0 & 0 & & \\
\hline Total & 4 & 9 & & \\
\hline Frequency of allele D, \% & 0 & 0 & & \\
\hline
\end{tabular}

\section{Characterization of Inhibitor-1 G147D in Heart}

\section{Failure Patients}

Consistently, the G147D genetic variant of inhibitor-1 was identified only in black heart failure patients. There were 28 heterozygous and 1 homozygous carriers among 288 patients, while this variant was not observed in 671 white patients (table 2). The black patients exhibited a frequency of $10.1 \%$ and an allele frequency of $5.21 \%$, while the black normal population indicated a similar distribution, with a frequency of $12.5 \%$ and an allele frequency of $6.25 \%$. There was 1 white normal subject out of 312 screened, who exhibited the G147D polymorphism $(0.16 \%$ allele frequency) (table 2). The inhibitor-1 genetic variant was found at allele frequencies consistent with the prediction of Hardy-Weinberg equilibrium ( $\mathrm{p}=1.000$ in normal black subjects, 0.549 in black patients).

\section{Association Analysis of Inhibitor-1 G147D with \\ Human Heart Failure}

Analysis of the clinical data of black heart failure patients revealed that carriers and noncarriers are compatible with age, gender, weight, height, blood pressure, primary diagnosis, other risk factors and medications (table 3). As mentioned above, there was only one homozygous carrier (DD), which precluded comparison of specific characteristics between heterozygous and homozygous carriers. Thus, the clinical parameters in G147D and D147D carriers were combined and compared to wild types (GG). This polymorphism was not directly associated with deteriorated cardiac function, as was evaluated by echocardiographic parameters including LVEF, LVEDD, LVESD, fractional shortening, septal thickness and postal wall thickness.

Kaplan-Meier analysis revealed that there were no significant differences in the pattern of endpoint event occurrence (we defined endpoint events as cardiac-associated death or cardiac transplantation) between G147D carriers and noncarriers in black heart failure patients by a 10-year follow-up since the first diagnostic date (fig. 1, $\log$-rank $\mathrm{p}=0.334)$. Unfortunately, too few cases, especially for the G147D carriers, were observed beyond 10 years, which precluded us from further exploring longerterm survival. In addition, Cox regression analysis was conducted to reveal a potential association between any of four variables including genotype, gender, body weight and $\beta$-blocker usage and the occurrence of cardiac-associated death or heart transplantation. It appears that only body weight was significantly associated with the frequency of the endpoint events, when effects from the other three factors were excluded based on the patient information (data not shown).

Based on the fact that overexpressing this polymorphism in isolated adult rat cardiomyocytes interfered with the contractile responses to $\beta$-adrenergic agonists 
Table 3. Clinical characteristics of black heart failure patients by inhibitor-1 genotype

\begin{tabular}{|c|c|c|c|c|c|}
\hline \multirow[t]{2}{*}{ Variable } & \multicolumn{2}{|l|}{ GG } & \multicolumn{2}{|c|}{ GD/DD } & \multirow[t]{2}{*}{$\mathrm{p}$ value } \\
\hline & $\mathrm{n}$ & mean $\pm \mathrm{SD}$ & $\mathrm{n}$ & mean $\pm \mathrm{SD}$ & \\
\hline Age at onset of heart failure, years & 251 & $52.97 \pm 13.06$ & 29 & $50.38 \pm 16.47$ & 0.326 \\
\hline Weight, kg & 245 & $89.34 \pm 25.07$ & 28 & $99.66 \pm 34.09$ & 0.131 \\
\hline Height, $\mathrm{cm}$ & 236 & $171.83 \pm 10.79$ & 28 & $170.5 \pm 7.67$ & 0.525 \\
\hline Systolic BP, mm Hg & 198 & $120 \pm 23.96$ & 27 & $113.85 \pm 23.06$ & 0.157 \\
\hline Diastolic BP, mm Hg & 198 & $75.45 \pm 14.49$ & 27 & $72.42 \pm 15.37$ & 0.32 \\
\hline LVEDD, $\mathrm{cm}$ & 217 & $6.10 \pm 1.04$ & 29 & $6.06 \pm 0.88$ & 0.839 \\
\hline LVESD, $\mathrm{cm}$ & 215 & $4.82 \pm 1.29$ & 29 & $4.56 \pm 1.38$ & 0.318 \\
\hline Septal wall, $\mathrm{cm}$ & 212 & $1.13 \pm 0.29$ & 28 & $1.14 \pm 0.29$ & 0.807 \\
\hline Posterior wall, $\mathrm{cm}$ & 212 & $1.03 \pm 0.27$ & 28 & $1.10 \pm 0.26$ & 0.164 \\
\hline LVEF, \% & 215 & $44.76 \pm 14.09$ & 29 & $43.64 \pm 13.78$ & 0.735 \\
\hline Fractional shortening, \% & 215 & $22.02 \pm 11.40$ & 29 & $25.95 \pm 14.70$ & 0.094 \\
\hline $\mathrm{MVO}_{2}$ & 117 & $15.66 \pm 5.03$ & 13 & $15.88 \pm 5.94$ & 0.881 \\
\hline \multirow[t]{2}{*}{ Variable } & \multicolumn{2}{|l|}{ GG } & \multicolumn{2}{|c|}{ GD/DD } & \multirow[t]{2}{*}{$\mathrm{p}$ value } \\
\hline & $\mathrm{n}$ & $\%$ & $\mathrm{n}$ & $\%$ & \\
\hline Male & 136 & 54.2 & 16 & 55.2 & 0.919 \\
\hline \multicolumn{6}{|l|}{ Primary diagnosis } \\
\hline Idiopathic cardiomyopathy & 154 & 64.2 & 17 & 58.6 & \\
\hline Coronary artery disease & 37 & 15.4 & 6 & 20.7 & \\
\hline Other & 49 & 20.4 & 6 & 20.7 & 0.75 \\
\hline Cardiac-related death or received transplant & 59 & 33.9 & 8 & 36.4 & 0.791 \\
\hline \multicolumn{6}{|l|}{ Other risk factors or coexisting conditions } \\
\hline Hypertension & 195 & 78.3 & 26 & 89.7 & 0.152 \\
\hline Diabetes mellitus & 75 & 32.3 & 13 & 48.1 & 0.1 \\
\hline Hypercholesterolemia & 48 & 24.7 & 8 & 38.1 & 0.185 \\
\hline \multicolumn{6}{|l|}{ Tobacco use } \\
\hline Present user & 127 & 69 & 12 & 63.2 & \\
\hline Past only & 33 & 17.9 & 3 & 15.8 & \\
\hline Never & 24 & 13 & 4 & 21.1 & 0.627 \\
\hline \multicolumn{6}{|l|}{ Medications at entry } \\
\hline$\beta$-Blocker & 198 & 81.8 & 23 & 79.3 & 0.94 \\
\hline ACE inhibitor & 194 & 94.2 & 21 & 87.5 & 0.414 \\
\hline $\mathrm{ARB}$ & 35 & 34.7 & 2 & 22.2 & 0.698 \\
\hline Aldosterone blocker & 33 & 31.4 & 4 & 26.7 & 0.482 \\
\hline
\end{tabular}

GG = Major form of inhibitor-1 gene; GD/DD = heterozygous/homozygous inhibitor-1 G147D genetic variant; $\mathrm{BP}=$ blood pressure; $\mathrm{LVEDD}=$ left ventricular end-diastolic diameter; $\mathrm{LVESD}=$ left ventricular end-systolic diameter; $\mathrm{LVEF}=$ left ventricular ejection fraction; $\mathrm{MVO}_{2}=$ maximum amount of oxygen that can be removed from circulating blood and used by the working tissues during a specified period; ACE inhibitor $=$ angiotensin-converting enzyme inhibitor; $\mathrm{ARB}=$ angiotensin receptor-blocking agent.

[15], it was interesting to assess whether the G147D inhibitor-1 carriers exhibited different contractile parameters in response to treatment with $\beta$-adrenergic blockers. However, no differences in terms of cardiac function or wall thickness were observed following $\beta$-blocker treatment in either G147D carriers or noncarriers (table 4).

\section{Discussion}

As a leading cause of mortality and morbidity worldwide, heart failure has been well-recognized as a multifactorial disease. Indeed, an increasing number of polymorphisms and mutations in signaling components regulating cardiac contractile function have been found to 
Table 4. Response to $\beta$-blocker treatment in black heart failure patients by inhibitor-1 genotype

\begin{tabular}{|c|c|c|c|c|c|c|c|c|c|c|}
\hline \multirow[t]{3}{*}{ Variable } & \multicolumn{4}{|c|}{$\mathrm{GD} / \mathrm{DD}$} & \multirow[t]{3}{*}{$\mathrm{p}$} & \multicolumn{4}{|c|}{ GG } & \multirow[t]{3}{*}{$\mathrm{p}$} \\
\hline & \multicolumn{2}{|c|}{ non-BB takers } & \multicolumn{2}{|c|}{ BB takers } & & \multicolumn{2}{|c|}{ non-BB takers } & \multicolumn{2}{|c|}{ BB takers } & \\
\hline & $\mathrm{n}$ & mean $\pm \mathrm{SD}$ & $\mathrm{n}$ & mean $\pm \mathrm{SD}$ & & $\mathrm{n}$ & mean $\pm \mathrm{SD}$ & $\mathrm{n}$ & mean $\pm \mathrm{SD}$ & \\
\hline Age at enrollment, years & 6 & $52.32 \pm 15.78$ & 23 & $49.86 \pm 16.91$ & 0.751 & 45 & $51.05 \pm 14.03$ & 206 & $53.41 \pm 12.84$ & 0.273 \\
\hline Weight, kg & 6 & $100.64 \pm 26.66$ & 23 & $103.78 \pm 36.89$ & 0.296 & 45 & $85.93 \pm 24.64$ & 206 & $89.89 \pm 24.52$ & 0.327 \\
\hline Height, $\mathrm{cm}$ & 6 & $165.74 \pm 8.02$ & 23 & $167.04 \pm 21.97$ & 0.888 & 45 & $170.72 \pm 10.94$ & 206 & $170.85 \pm 15.65$ & 0.957 \\
\hline LVEDD, $\mathrm{cm}$ & 5 & $6.60 \pm 0.70$ & 22 & $6.00 \pm 0.90$ & 0.183 & 36 & $6.10 \pm 1.28$ & 190 & $6.13 \pm 0.99$ & 0.883 \\
\hline LVESD, cm & 5 & $5.26 \pm 1.39$ & 22 & $4.55 \pm 1.32$ & 0.294 & 36 & $4.78 \pm 1.39$ & 189 & $4.85 \pm 1.24$ & 0.750 \\
\hline Septal wall, $\mathrm{cm}$ & 4 & $0.90 \pm 0.24$ & 22 & $1.19 \pm 0.29$ & 0.078 & 36 & $1.13 \pm 0.24$ & 190 & $1.12 \pm 0.28$ & 0.838 \\
\hline Posterior wall, $\mathrm{cm}$ & 4 & $1.03 \pm 0.26$ & 21 & $1.10 \pm 0.27$ & 0.570 & 35 & $1.04 \pm 0.23$ & 177 & $22.25 \pm 0.27$ & 0.645 \\
\hline Fractional shortening, $\%$ & 4 & $21.32 \pm 13.30$ & 16 & $25.19 \pm 13.61$ & 0.570 & 29 & $22.68 \pm 10.18$ & 160 & $23.71 \pm 12.51$ & 0.849 \\
\hline LVEF, \% & 4 & $40.52 \pm 19.19$ & 16 & $44.42 \pm 12.79$ & 0.626 & 29 & $45.52 \pm 13.88$ & 160 & $44.62 \pm 14.17$ & 0.754 \\
\hline
\end{tabular}

GD/DD = Heterozygous/homozygous inhibitor-1 G147D genetic variant; GG = major form of inhibitor-1 gene; BB takers = $\beta$ blocker takers; LVEDD = left ventricular end-diastolic diameter; LVESD = left ventricular end-systolic diameter; LVEF = left ventricular ejection fraction.

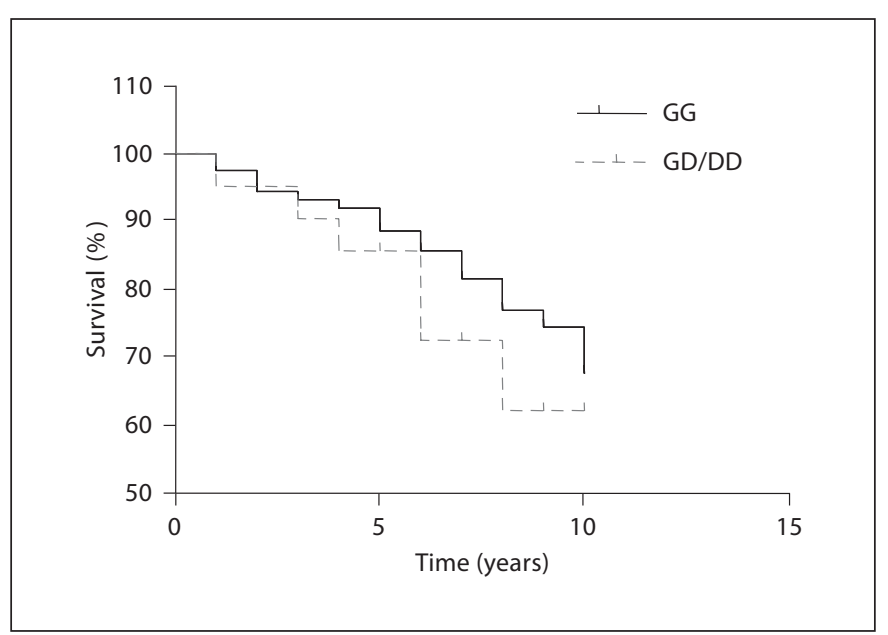

Fig. 1. Kaplan-Meier estimates of transplant-free survival. The survival rates were compared between G147D carriers (GD/DD) and noncarriers (GG) in black heart failure patients for a 10 -year term. Curves were compared using the log-rank test. The overall pattern of event-free survival was not different $(p=0.334)$ between the two groups.

be linked to dilated cardiomyopathy or propensity to arrhythmias [17-21]. For example, multiple human polymorphisms on adrenergic signaling pathways have been reported to be direct or conjunct factors affecting development, prognosis or therapy of heart failure [17, 22-25]. PP1 inhibitor-1 has recently emerged as an important regulator for cardiac contractile function by maintaining an appropriate phosphorylation level of cardiac proteins and serving as a downstream mediator in the $\beta$-adrenergic signaling pathway. Moreover, reduced protein levels or activity of this molecule have been linked to experimental and human heart failure [4, 12-14]. In this study, we screened the inhibitor-1 gene in heart failure patients and cohort normal subjects in order to identify genetic variants, possibly associated with the onset, progression and/or prognosis of heart failure. Interestingly, the G147D inhibitor-1 genetic variant was found almost exclusively in the black population.

Notably, the human inhibitor-1 variant, G147D, is located close to the C-terminus of the protein, which may be important for its activity [26]. A recent study in isolated adult rat cardiomyocytes revealed that overexpression of this human inhibitor-1 polymorphism blunted the cell's responses to $\beta$-adrenergic agonists in regard to contractility and Ca cycling by reducing the phosphorylation levels of phospholamban [15]. The present study analyzed the patients' clinical history, but there were no alterations in any of the evaluated functional parameters or their responses to $\beta$-blocker treatment elicited by the inhibitor-1 polymorphism. However, this apparent discrepancy between findings in isolated cardiomyocytes [15] and heart failure patients should be interpreted with caution, given the complexities in translating a cellular response to an in vivo phenotype. An additional confounding factor in defining the clinical significance of the G147D inhibitor-1 may be the low prevalence of this polymorphism in the human population. 
While the inhibitor-1 variant clearly had physiological significance in isolated cardiac myocytes, it was not an independent risk factor for heart failure in humans, as the prevalence was similar in normal subjects and the heart failure cohort and major cardiac functional parameters were not significantly altered in G147D carriers compared to noncarriers in the heart failure patients. However, this genetic variant may elicit measurable consequences in human disease in the context of other polymorphisms that already impact cardiac function. For example, polymorphisms of $\beta_{1^{-}}$(Arg89) and $\alpha_{2 c^{-}}$(Del22325 ) adrenergic receptors act synergistically to increase the risk of human heart failure [27]. In addition, increasing evidence has indicated that the increased prevalence of genetic variants may contribute to the development and outcome of heart failure in blacks [28-30]. In particular, multiple polymorphisms of the adrenergic signaling pathways have been linked to the increased risk and worse prognosis of heart failure for black patients [22, 27]. Therefore, given the lack of statistical power in identifying an apparent correlation between the G147D inhibitor-1 polymorphism and clinical parameters, we can speculate that the G147D genetic variant may have a rather small adverse biological effect on its own. However, it may contribute to a multigenetic predisposition to ad- verse heart failure outcomes in blacks. Alternatively, the presence of other frequent mutant alleles found in the black population [22, 27-30], as outlined above, may act as confounding factors in the development and/or progression of heart failure. However, lack of information on the presence of other functionally significant mutations or polymorphisms in our cohort prevents further evaluation of this hypothesis. To further define such potential gene-gene interactions, studies in a much larger population with genotyping of entire functional clusters of $\beta$ adrenergic signaling factors and their downstream signaling effectors and targets will be required.

Overall, the present findings suggest that the G147D genetic variant of inhibitor-1 may not play an independent role in human heart failure, but may be a contributing factor to the deteriorated cardiac function acting as one of the modifiers for this disease.

\section{Acknowledgments}

This work was supported by NIH grants HL-26507, HL-64018, and HL-77101, the Leducq Foundation and an AHA postdoctoral fellowship 0525435B (to G.C.).

\section{References}

1 Marian AJ: Beta-adrenergic receptors signaling and heart failure in mice, rabbits and humans. J Mol Cell Cardiol 2006;41:11-13.

$\checkmark 2$ Feldman DS, Carnes CA, Abraham WT, Bristow MR: Mechanisms of disease: betaadrenergic receptors - alterations in signal transduction and pharmacogenomics in heart failure. Nat Clin Pract Cardiovasc Med 2005;2:475-483.

$\checkmark 3$ Bers DM: Cardiac excitation-contraction coupling. Nature 2002;415:198-205.

$\checkmark 4$ Carr AN, Schmidt AG, Suzuki Y, del Monte F, Sato Y, Lanner C, Breeden K, Jing SL, Allen PB, Greengard P, Yatani A, Hoit BD, Grupp IL, Hajjar RJ, DePaoli-Roach AA, Kranias EG: Type 1 phosphatase, a negative regulator of cardiac function. Mol Cell Biol 2002;22: 4124-4135.

5 Gupta RC, Neumann J, Watanabe AM, Lesch M, Sabbah HN: Evidence for presence and hormonal regulation of protein phosphatase inhibitor-1 in ventricular cardiomyocyte. Am J Physiol 1996;270:H1159-H1164.
6 Neumann J, Eschenhagen T, Jones LR, Linck B, Schmitz W, Scholz H, Zimmermann N: Increased expression of cardiac phosphatases in patients with end-stage heart failure. J Mol Cell Cardiol 1997;29:265-272.

-7 Gupta RC, Mishra S, Rastogi S, Imai M, Habib O, Sabbah HN: Cardiac SR-coupled PP1 activity and expression are increased and inhibitor 1 protein expression is decreased in failing hearts. Am J Physiol Heart Circ Physiol 2003;285:H2373-H2381.

-8 Pathak A, del Monte F, Zhao W, Schultz JE, Lorenz JN, Bodi I, Weiser D, Hahn H, Carr AN, Syed F, Mavila N, Jha L, Qian J, Marreez Y, Chen G, McGraw DW, Heist EK, Guerrero JL, DePaoli-Roach AA, Hajjar RJ, Kranias EG: Enhancement of cardiac function and suppression of heart failure progression by inhibition of protein phosphatase 1. Circ Res 2005;96:756-766

9 Ahmad Z, Green FJ, Subuhi HS, Watanabe AM: Autonomic regulation of type 1 protein phosphatase in cardiac muscle. J Biol Chem 1989;264:3859-3863.
10 Endo S, Zhou X, Connor J, Wang B, Shenolikar S: Multiple structural elements define the specificity of recombinant human inhibitor-1 as a protein phosphatase-1 inhibitor. Biochemistry 1996;35:5220-5228.

11 El-Armouche A, Rau T, Zolk O, Ditz D, Pamminger T, Zimmermann WH, Jackel E, Harding SE, Boknik P, Neumann J, Eschenhagen $\mathrm{T}$ : Evidence for protein phosphatase inhibitor-1 playing an amplifier role in beta-adrenergic signaling in cardiac myocytes. FASEB J 2003;17:437-439.

12 El-Armouche A, Pamminger T, Ditz D, Zolk $\mathrm{O}$, Eschenhagen T: Decreased protein and phosphorylation level of the protein phosphatase inhibitor-1 in failing human hearts. Cardiovasc Res 2004;61:87-93.

$>13$ Gupta RC, Mishra S, Yang XP, Sabbah HN: Reduced inhibitor 1 and 2 activity is associated with increased protein phosphatase type 1 activity in left ventricular myocardium of one-kidney, one-clip hypertensive rats. Mol Cell Biochem 2005;269:49-57. 
14 El-Armouche A, Gocht F, Jaeckel E, Wittkopper K, Peeck M, Eschenhagen T: Longterm beta-adrenergic stimulation leads to downregulation of protein phosphatase inhibitor-1 in the heart. Eur J Heart Fail 2007; 9:1077-1080.

-15 Chen G, Zhou X, Nicolaou P, Rodriguez P, Song G, Mitton B, Pathak A, Zachariah A, Fan GC, Dorn GW 2nd, Kranias EG: A human polymorphism of protein phosphatase1 inhibitor-1 is associated with attenuated contractile response of cardiomyocytes to beta-adrenergic stimulation. FASEB J 2008; 22:1790-1796.

- 16 Haghighi K, Chen G, Sato Y, Fan GC, He S, Kolokathis F, Pater L, Paraskevaidis I, Jones WK, Dorn GW 2nd, Kremastinos DT, Kranias EG: A human phospholamban promoter polymorphism in dilated cardiomyopathy alters transcriptional regulation by glucocorticoids. Hum Mutat 2008;29:640647.

17 Liggett SB: Polymorphisms of beta-adrenergic receptors in heart failure. Am J Med 2004;117:525-527.

18 Taylor MR, Bristow MR: Alterations in myocardial gene expression as a basis for cardiomyopathies and heart failure. Novartis Found Symp 2006;274:73-83, 152-155, 272276.

19 Haghighi K, Kolokathis F, Fan GC, Sato Y, Kremastinos DT, Kranias EG: Phospholamban mutations in human dilated cardiomyopathy. Circulation 2004;110:1734.
20 Haghighi K, Kolokathis F, Pater L, Lynch RA, Asahi M, Gramolini AO, Fan GC, Tsiapras D, Hahn HS, Adamopoulos S, Liggett SB, Dorn GW 2nd, MacLennan DH, Kremastinos DT, Kranias EG: Human phospholamban null results in lethal dilated cardiomyopathy revealing a critical difference between mouse and human. J Clin Invest 2003;111:869-876.

21 Haghighi K, Kolokathis F, Gramolini AO, Waggoner JR, Pater L, Lynch RA, Fan GC, Tsiapras D, Parekh RR, Dorn GW 2nd, MacLennan DH, Kremastinos DT, Kranias EG: A mutation in the human phospholamban gene, deleting arginine 14, results in lethal, hereditary cardiomyopathy. Proc Natl Acad Sci USA 2006;103:1388-1393.

-22 Liggett SB, Kelly RJ, Parekh RR, Matkovich SJ, Benner BJ, Hahn HS, Syed FM, Galvez AS, Case KL, McGuire N, Odley AM, Sparks L, Kardia SL, Dorn GW 2nd: A functional polymorphism of the Galphaq (GNAQ) gene is associated with accelerated mortality in African-American heart failure. Hum Mol Genet 2007;16:2740-2750.

23 Kovlen DV, Tishakov AY, Glotov OS, Moskalenko MV, Demin GS, Bitsadze AN, Chernyshev AV, Bratova NI, Ivashchenko TE, Obrezan AG, Ponomarenko GN: Genetic determinants of the efficiency of climatotherapy in patients with chronic heart failure. Bull Exp Biol Med 2007;143:26-31.

24 Barbato E, Penicka M, Delrue L, Van Durme F, De Bruyne B, Goethals M, Wijns W, Vanderheyden M, Bartunek J: Thr164Ile polymorphism of beta2-adrenergic receptor negatively modulates cardiac contractility: implications for prognosis in patients with idiopathic dilated cardiomyopathy. Heart 2007;93:856-861.
25 Brodde OE: Beta-1 and beta-2 adrenoceptor polymorphisms: functional importance, impact on cardiovascular diseases and drug responses. Pharmacol Ther 2008;117: $1-29$.

26 Weiser DC, Sikes S, Li S, Shenolikar S: The inhibitor-1 $\mathrm{C}$ terminus facilitates hormonal regulation of cellular protein phosphatase1: functional implications for inhibitor-1 isoforms. J Biol Chem 2004;279:4890448914.

27 Small KM, Wagoner LE, Levin AM, Kardia SL, Liggett SB: Synergistic polymorphisms of beta1- and alpha2C-adrenergic receptors and the risk of congestive heart failure. $\mathrm{N}$ Engl J Med 2002;347:1135-1142.

-28 McNamara DM, Tam SW, Sabolinski ML, Tobelmann P, Janosko K, Taylor AL, Cohn JN, Feldman AM, Worcel M: Aldosterone synthase promoter polymorphism predicts outcome in African Americans with heart failure: results from the A-HeFT Trial. J Am Coll Cardiol 2006;48:1277-1282.

29 Yancy CW: Does race matter in heart failure? Am Heart J 2003;146:203-206.

30 Biolo A, Chao T, Duhaney TA, Kotlyar E, Allensworth-Davies D, Loscalzo J, Sam F: Usefulness of the aldosterone synthase gene polymorphism C-344-T to predict cardiac remodeling in African-Americans versus non-African-Americans with chronic systolic heart failure. Am J Cardiol 2007;100: 285-290. 